\title{
SOCIAL MEDIA MARKETING ON INSTAGRAM: WHEN IS THE MOST EFFECTIVE POSTING TIMING?
}

\author{
Risqo M. Wahid ${ }^{1}$ \\ ${ }^{1}$ Lecturer, \\ Faculty of Economics, \\ Universitas Indo Global Mandiri, \\ Palembang, \\ Indonesia
}

\author{
Muhammad Wadud ${ }^{2}$ \\ ${ }^{2}$ Assistant Professor, \\ Faculty of Economics, \\ Universitas Indo Global Mandiri, \\ Palembang, \\ Indonesia
}

Article DOI: https://doi.org/10.36713/epra4834

\begin{abstract}
This study investigates the most effective posting timing on Instagram to enhance content engagements (i.e., likes and comments). Data of 2,958 Indonesian food brands posts were analysed using negative binomial regression to predict the number of likes and comments. This study reveals that the most effective posting days are on Monday, Tuesday, Wednesday, Thursday, and Friday as contents posted on Instagram on these days result in a higher number of likes and comments. In addition, this study also encourages food brands to post their contents during breakfast and lunch times as these times of the day prompt more likes and comments. The findings of this study will help brands and social media managers to include scheduling in their social media marketing strategy on Instagram.
\end{abstract}

KEYWORDS: Social Media Marketing, Instagram, Posting Days, Posting Times, Content Engagement

\section{INTRODUCTION}

Brands employ social media as a part of their marketing mix due to the relatively low cost, interactivity, global reach, and access to data and analytics (Pinto and Yagnik, 2017). Through these features, research reveals that social media marketing improves both financial and non-financial performances (e.g., cost reduction in marketing and customer service, enhanced customer relations and information accessibility) (Ainin et al., 2015). Among numerous social media platforms, brands should consider Instagram. This medium has one billion monthly active users; 200 millions of them visit at least one business profile every day (Newberry, 2019); 50\% of users follow at least one brand; helps $80 \%$ of its users on deciding whether to purchase a product or service; and can generate four times more interactions compared to Facebook (Mohsin, 2020). Besides, people spend more time on it compared to other social media platforms (Vries, 2019). Although Instagram offers substantial opportunities, strategies are still required to achieve success.

In the social media marketing sphere, high content engagement (e.g., number of likes and comments) exhibits effective programme implementation (Schreiner, Fischer and Riedl, 2019).
Among other variables, as proven by previous studies (Pletikosa Cvijikj and Michahelles, 2013; Sabate et al., 2014), scheduling posting time can influence likes and comments both positively and negatively. Hence knowing when to share contents will determine the performance of the content engagement. Nevertheless, brands should be aware that despite the empirical findings, the analyses focus only on Facebook. The results might be inapplicable for Instagram. Concerning this matter, those studies, as mentioned earlier, further suggest analysing factors driving content engagement (e.g., posting timing) on other social media platforms.

The discussion of Instagram posting timing is all from blogs on the internet. Jones (2020), Loren (2020), and Chi (2020) argue that Instagram algorithm prioritises new contents to show on users' feed. Consequently, brands should schedule their posts when their target audience is browsing Instagram in order to foster engagement (e.g., likes and comments) potentially. This suggestion, however, is neither verifiable, in the form of formal studies, nor based on grounded theory.

To address these research gaps, this study aims to unveil the most effective posting timing on Instagram. This study offers two contributions to social media marketing literature. First, it answers the call from previous studies to explore factors driving 
content engagement (e.g., posting timing) on social media platforms other than Facebook. Second, this study provides an empirical and formal study for posting timing on Instagram. In the practical perspective, the results of this research can guide social media marketers and brand owners to schedule their posts on Instagram. The implementation of this strategy will help them to obtain higher content engagement that eventually might lead to increased consumers loyalty, purchase intention, and others.

\section{LITERATURE REVIEW \\ 2.1Content Engagement}

In social media marketing (SMM) studies (de Vries, Gensler and Leeflang, 2012; Pletikosa Cvijikj and Michahelles, 2013; Schreiner, Fischer and Riedl, 2019), content engagement and consumer engagement are often interchangeable. This study of SMM pointedly refers to content engagement as a theoretical framework. In this digital marketing era, brands and marketers pay attention to nontransactional customer behaviour (Pletikosa Cvijikj and Michahelles, 2013), in this case, content engagement. On online platforms, the term represents the measurable results of individual interaction with content on social media channels (Schreiner, Fischer and Riedl, 2019). These measurements are in the forms of likes, comments, shares (Pletikosa Cvijikj and Michahelles, 2011, 2013; de Vries, Gensler and Leeflang, 2012; Sabate et al., 2014; Luarn, Lin and Chiu, 2015; Schultz, 2017), click-through rates (CTR), page views, and others depending on the service and tools offered by the platforms (Lehmann et al., 2012).

Research shows that consumers who actively connect with brands' social media contents have stronger relationships with the respective brands compared to those consumers who avoid the connection (Hudson et al., 2016). Studies further substantiate that content engagements affect consumer value (Schau, Jr and Arnould, 2009), trust (Casaló, Flavián and Guinalíu, 2007), brand evaluations, and purchase intention (Beukeboom, Kerkhof and de Vries, 2015). After achieving these marketing objectives, positive content engagement on social media eventually leads to sales and profitability (Rishika et al., 2013). Beyond these benefits, studies verify that consumers who engage with brands on social media platforms can help brands providing value as co-creators in business processes, such as for market analysis, product development, and recommendations (De Vries and Carlson, 2014; Kabadayi and Price, 2014).

Given the favourable effects of content engagement, studies have investigated factors influencing it (Pletikosa Cvijikj and Michahelles, 2011, 2013; de Vries, Gensler and Leeflang, 2012;
Sabate et al., 2014; Luarn, Lin and Chiu, 2015; Schultz, 2017). One of the aspects is posting timing. Those discussions nonetheless concentrate only on Facebook. This present research attempts to provide insights from other social media platform (i.e., Instagram) and corroborate the previous investigations. In terms of content engagement measurements, previous studies on Facebook (Pletikosa Cvijikj and Michahelles, 2011, 2013; de Vries, Gensler and Leeflang, 2012; Sabate et al., 2014; Luarn, Lin and Chiu, 2015; Schultz, 2017) use likes, comments, and shares. They took these variables because they are publicly available on Facebook. For Instagram, this platform provides various measurements (e.g., reach, saves, shares, and impressions) for brand profiles. Some of this information, however, is only for the private use of the relative brands. This study of Instagram measures its content engagement through likes and comments because only these two data are available for the public.

\subsection{Posting Days}

On Facebook, posts originating from multiple sources (e.g., friends, groups, and brands) overload users' home feeds (Pletikosa Cvijikj and Michahelles, 2013). This condition also applies to users on Instagram. As such, brands' contents are likely to be stacked and hidden from users. This problem emphasises the significance of scheduling inclusion in marketing strategy (Kumar, Jacob and Sriskandarajah, 2006).

Previous studies on content engagement reveal inconclusive findings regarding the effect of posting days on likes and comments. De Vries et al. (2012), Sabate et al. (2014), and Schultz (2017) categorise the posting days into weekdays and weekends. These researchers evidence there are no significant effects of posting days on likes and comments. This indicates that posting on weekdays or weekends leads to neither higher nor lower number of likes and comments. However, it should be noted that these analyses investigate diverse industry using a limited amount of data. Pletikosa Cvijikj and Michahelles (2013) inspect food and beverage industry processing 5035 data. They reveal that posting contents on weekdays decreases the number of likes but increases the number of comments. This present research examines food brands with more than 2,000 cases. Hence the hypotheses for the effect of posting days on likes and comments are based on the latter study. The predictions are as follows:

H1a: Contents posted during Weekdays (Mondays, Tuesdays, Wednesday, Thursday, and Friday) result in a lower number of likes 
H1b: Contents posted Weekdays (Mondays, Tuesdays, Wednesday, Thursday, and Friday) result in a higher number of comments

\subsection{Posting Times}

Social media users engage least during morning and early afternoon and interact the most during the late afternoon and evening (Golder, Wilkinson and Huberman, 2007; Lagrosen and Grundén, 2014). Contrary to this statement, empirical examinations provide mixed results. Sabate et al. (2014) investigate the effect of posting on business hours toward likes and comments on Facebook. They evidence that there is no significant effect for likes but significant and positive for comments. Further, Pletikosa Cvijikj and Michahelles (2013) divide the posting time into low hours (4 a.m. to 4 p.m.) and peak hours (4 p.m. to 4 a.m.). They found that Facebook users give more likes to contents posted during low hours compared to peak hours.

This study categorises posting times into breakfast (6 a.m. to 10 a.m.), lunch (11 a.m. to 3 p.m.), dinner (6 p.m. to 9 p.m.), and in-between (other than the hours as mentioned earlier). Referring to Pletikosa (2013), breakfast and lunch periods in this study include in the low hours category. On the other hand, dinner and in-between times are mostly in the peak hours group. Thus, according to Pletikosa Cvijikj and Michahelles (2013) and Sabate et al. (2014), this study predicts:

H2a: Contents posted during breakfast result in a higher number of likes

$\mathrm{H} 2 \mathrm{~b}$ : Contents posted during lunch result in a higher number of likes

$\mathrm{H} 2 \mathrm{c}$ : Contents posted during dinner result in a lower number of likes

$\mathrm{H} 2 \mathrm{~d}$ : Contents posted during breakfast result in a higher number of comments

H2e: Contents posted during lunch result in a higher number of comments

H2f: Contents posted during dinner result in a lower number of comments.

\subsection{Control Variable}

Research proves that the number of followers positively affect numbers of likes and comments on social media (Sabate et al., 2014). Additionally, de Vries (2019) states that social media users (e.g., individuals, influencers, and brands) are likely to purchase fake followers and likes to create inferences on the popularity of their social media accounts and contents. This impression of quality, in the end, will prompt followers to give more likes and comments. Lastly, studies reveal that remuneration affects likes (de Vries, Gensler and Leeflang, 2012; Luarn, Lin and Chiu, 2015) and comments (Pletikosa Cvijikj and Michahelles, 2013; Schultz, 2017). Due to these reasons, this study includes the number of followers, fake followers, fake likes, and remuneration as control variables.

\section{METHODOLOGY \\ 3.1 Data Collection}

Studies collecting posts from Instagram and analysing its content engagement (e.g., number of likes and comments) are still scarce (Schreiner, Fischer and Riedl, 2019). Most of them are from Facebook, and there are no generally accepted sampling procedures such as the number of brands, popularity categorisation, and data collection duration (McCorkindale, 2010; Bender, JimenezMarroquin and Jadad, 2011; Wallace, Wilson and Miloch, 2011; de Vries, Gensler and Leeflang, 2012; Shen and Bissell, 2013; Pinto and Yagnik, 2017). In this research, the investigation involved 40 Indonesian food brands (i.e., restaurants, packaged local snacks, street food, and pastry) whose more than 20,000 followers on Instagram. The sampling duration was one month, from 1 September 2019 to 30 September 2019. The total posts collected were 2,958 , and they were the coding and analytical units for the analysis.

This study appointed 5 trained research assistants to collect the data. They conducted the procedures manually by using the Excel code sheet to record the information. Notably, for posting times, the process included visiting the brands' Instagram profiles, clicking on the posts, and inspecting the embedded codes. The time used was Western Indonesia Time (UTC+07:00). This study selected 4 random post dates from each account and checked the posting times to ensure validity. From a total of 160 random samples, there were no error data. In terms of the periods of the posts, this study divided them into 4 categories; from 6 a.m. to 10 a.m. is breakfast; 11 a.m. to 3 p.m. is lunch; 6 p.m. to 9 p.m. is dinner; the rest of the hours are in-between.

Furthermore, this study determined the control variables of followers and likes types (i.e., real or fake) according to the ratios of Angulo (2016), Tomov (2019), and Osman (2020). For the followers' types of each brand, the process began by calculating the average likes and comments the respective brand received during the one-month observation. These figures then were divided by the number of followers to obtain the likes-to-followers and comments-tofollowers ratios, respectively. For the brands that owned 10,000 to 100,000 followers, if the likes-tofollowers ratio $<2.37 \%$ and the comments-tofollowers ratio $<0.17 \%$, then the Instagram brand accounts had a substantial number of fake followers. For the brands that owned more than 100,000 to $1,000,000$ followers, if the likes-to-followers ratio $<1.78 \%$ and comments-to-followers 
ratio $<0.09 \%$, then the Instagram brand accounts had a substantial number of fake followers. For the types of likes variable, this study divided the likes each post received by the number of followers the respected brand owned. If the likes-to-followers ratio $>7 \%$, then the post had a substantial number of fake likes. For the remuneration variable, if the posts contained remuneration in the picture or caption (e.g., buy one free one, discounts, or other forms of remuneration), then the research assistants coded them as remunerated.

\subsection{Analysis Method}

Dependent variables of this study are count data of the number of likes and comments. The variances of these data are much higher than their means. As such, these data are overdispersed. To overcome the problem, this study employs Negative Binomial in the analysis (Cameron and Trivedi, 2013), following Pletikosa Cvijikj and Michahelles (2013). The model to explain the number of likes and the number of comments based on days can be expressed as:

$$
\log \left(y_{i j}\right)=\alpha+\sum_{d=1}^{6} \beta_{d} \text { days }_{d j}+\beta_{f} \log \left(\text { nfollowers }_{j}\right)+\beta_{f} \text { follow }_{j}+\beta_{l} \text { likes }_{j}+\beta_{p} \text { remu }_{j}
$$

where

$\mathrm{y}_{\mathrm{ij}}$

days $_{\mathrm{dj}}$

$y_{1 j}$ or $y_{2 j}$; the number of likes per brand post $\mathrm{j}$ or the number of comments per brand post $\mathrm{j}$, respectively,

dummy variables post $j$ was posted at day $d$ (baseline category is Sunday),

nfollowers $j_{j}$ indicating the number of followers the brands have during brand post $j$,

follow $_{\mathrm{j}} \quad$ dummy variable indicating whether brand post $j$ was posted by brands with a substantial number of fake followers (baseline real followers),

likes $_{j}$ dummy variable indicating whether brand post $j$ has a substantial number of fake likes (baseline real likes),

$\mathrm{remu}_{\mathrm{j}}$ dummy variable indicating whether brand post $j$ contains remuneration (baseline no remuneration).

The model to explain the number of likes and the number of comments based on eating times can be expressed as:

$$
\log \left(y_{i j}\right)=\alpha+\sum_{e=1}^{3} \beta_{e} \text { periods }_{e j}+\beta_{f} \log (\text { nfollowers } j)+\beta_{f} \text { follow }_{j}+\beta_{l} \text { likes }_{j}+\beta_{p} \text { remu }_{j}
$$

where

$y_{i j} \quad y_{1 j}$ or $y_{2 j}$; the number of likes per brand post $\mathrm{j}$ or the number of comments per brand post $\mathrm{j}$, respectively,

periods $_{\mathrm{ej}} \quad$ dummy variables post $j$ was posted at eating period $e$ (baseline category is in-between),

nfollowers $\mathrm{j}_{\mathrm{j}}$ indicating the number of followers the brands have during brand post $j$,

follow $w_{j} \quad$ dummy variable indicating whether brand post $j$ was posted by brands with a substantial number of fake followers (baseline real followers),

likes $_{\mathrm{j}} \quad$ dummy variable indicating whether brand post $j$ has a substantial number of fake likes (baseline real likes),

$\mathrm{remu}_{\mathrm{j}} \quad$ dummy variable indicating whether brand post $j$ contains remuneration (baseline no remuneration).

\section{RESULTS \\ 4.1 Descriptive Statistics}

As seen in Table 1, the average total followers among the 40 brands were 82,760.50 $(\mathrm{SD}=109,637.72)$. For the posts during the onemonth observation, the total average likes the 40 brands received was $587.35(\mathrm{SD}=742.26)$, and the total average comments the 40 brands received was 24.18 ( $\mathrm{SD}=33.84)$. Using these figures, this study calculated the likes-to-followers and comments-tofollowers ratios for each brand. The analysis found that the total average likes-to-followers ratio was $1.25 \%(\mathrm{SD}=2.55 \%)$, and the total average commentsto-followers ratio was $0.04 \% \quad(\mathrm{SD}=0.05 \%)$. According to these ratios, among the 40 brands, the calculation revealed 35 brands had a substantial number of fake followers and the 5 brands had real followers.

Among the 2958 Instagram contents collected, as presented in Table 2, the most posts were on Sunday (19.5\%), followed by Saturday $(15.2 \%)$, 
Monday (15\%), Thursday (13.5\%), Tuesday (12.6\%), Friday $(12.2 \%)$, and the least posts were on Wednesday with $12 \%$. In terms of periods, the rank of the posts from highest to lowest was during lunch, dinner, in-between, and breakfast, with the percentage of $30 \%, 29.3 \%, 25.2 \%$, and $15.2 \%$, respectively. Among the 2958 posts, the average likes were $104.36(\mathrm{SD}=213.85)$, and the average comments were $3.46(\mathrm{SD}=10.81)$. For the control variables, 2878 posts were from brands with considerable numbers of fake followers and 80 were from brands with real followers; 1 posts received a substantial number of fake likes and 2957 obtained real likes; 50 posts contained remuneration, and 2908 posted no remuneration.

\subsection{Analysis Results}

\section{Likes and Comments Estimation Based on Days}

The model to estimate likes based on days is significant as a whole (LR $\chi^{2}(10, \mathrm{~N}=2958)=$ 1469.009, $p<0.001$ ) (see Table 3 ). In terms of individual days, contents posted during weekdays evidence significant and positive effects on likes (Monday $\quad\left(\beta_{\text {Monday }}=0.303, \quad p<0.01\right) ; \quad$ Tuesday $\left(\beta_{\text {Tuesday }}=0.322, \quad \quad \quad p<0.01\right) ; \quad$ Wednesday $\left(\beta_{\text {Wednesday }}=0.393, p<0.01\right)$; Thursday $\left(\beta_{\text {Thursday }}=0.262\right.$, $p<0.01)$; Friday $\left.\left(\beta_{\text {Friday }}=0.414, \quad p<0.01\right)\right)$. Also, contents posted on Saturday are marginally significant and positive $\left(\beta_{\text {Saturday }}=0.173, p<0.05\right)$, but still generating fewer likes compared to the weekdays. These findings show that contents posted during weekdays (Monday, Tuesday, Wednesday, Thursday, and Friday) result a higher number of likes, contrary to H1a.

The model to estimate comments based on days is significant as a whole $\left(\operatorname{LR} \chi^{2}(10, \mathrm{~N}=2958)=\right.$ $302.595, p<0.001)$. In terms of individual days, contents posted during weekdays evidences significant and positive effects on comments (Monday $\quad\left(\beta_{\text {Monday }}=0.595, \quad p<0.01\right)$; $\quad$ Tuesday $\left(\beta_{\text {Tuesday }}=0.705, \quad \quad \quad<<0.01\right) ; \quad$ Wednesday $\left(\beta_{\text {Wednesday }}=0.637, p<0.01\right)$; Thursday $\left(\beta_{\text {Thursday }}=0.528\right.$, $p<0.01)$; Friday $\left.\left(\beta_{\text {Friday }}=0.389, p<0.05\right)\right)$. In addition, posting contents on Saturday is not significantly related to the number of comments. These findings show that contents posted during weekdays (Monday, Tuesday, Wednesday, Thursday, and Friday) result in a higher number of comments, in support of H1b.

Likes and Comments Estimation Based on Times

The model to estimate likes based on eating times is significant as a whole $\left(\operatorname{LR} \chi^{2}(7, \mathrm{~N}=2958)=\right.$ 1497.904, $p<0.001$ ) (see Table 4). In terms of individual times, contents posted during breakfast have a significant and positive effect on likes $\left(\beta_{\text {Breaktas }}=0.298, p<0.01\right)$, supporting H2a. Likewise, contents posted during lunch have a significant and positive effect on likes $\left(\beta_{\text {Lunch }}=0.234, p<0.01\right)$, supporting H2b. Additionally, the model evidences that contents posted during dinner have a significant and negative effect on likes $\left(\beta_{\text {Dinner }}=-0.160, p<0.01\right)$, supporting $\mathrm{H} 2 \mathrm{c}$.

The model to estimate comments based on eating times is significant as a whole (LR $\chi^{2}$ (7, $\mathrm{N}=2958)=320.785, p<0.001$ ). In terms of individual times, contents posted during breakfast have a significant and positive effect on comments $\left(\beta_{\text {Breaktase }}=0.756, p<0.01\right)$, supporting H2d. Likewise, contents posted during lunch have a significant and positive effect on comments $\left(\beta_{\text {Lunch }}=0.376, p<0.01\right)$, supporting H2e. Additionally, the model evidences that contents posted during dinner is not significantly related to the number of comments $\left(\beta_{\text {Dinner }}=-0.160\right.$, $p<0.01)$, contrary to $\mathrm{H} 2 \mathrm{f}$.

\section{DISCUSSION \\ 5.1 Theoretical Implications}

Findings from previous studies (de Vries, Gensler and Leeflang, 2012; Sabate et al., 2014; Schultz, 2017) suggest that contents posted either during weekdays or weekends lead to neither higher nor lower content engagements (e.g., likes and comments). This statement indicates that scheduling is unnecessary in the social media marketing strategy. Contrary to this suggestion, this study on Instagram proves that posting timing determines the number of likes and comments brands' contents will generate. Specifically, brands should post their Instagram content on weekdays (i.e., Monday, Tuesday, Wednesday, Thursday, and Friday) instead of on weekends (i.e., Saturday and Sunday) to receive more likes. This evidence also contradicts to Pletikosa Cvijikj and Michahelles (2013), stating that contents posted during weekdays will result in a lower number of likes. In terms of comments, the results are in line with Pletikosa Cvijikj and Michahelles (2013). Contents posted during weekdays prompt a higher number of comments.

Concerning the times of the day, this study reveals that the number of likes for contents increases during breakfast and lunch and decreases during dinner posting times. These outcomes are contradictory with Sabate et al. (2014) but in line with Pletikosa Cvijikj and Michahelles (2013). Additionally, for comments prediction, contents posted during breakfast, as well as lunch, agree and during dinner disagree with those findings of Sabate et al. (2014) and Pletikosa Cvijikj and Michahelles (2013). Posting during breakfast and lunch on Instagram generates a higher number of comments, while during dinner, it causes neither higher nor lower number of comments.

Some aspects might cause distinction in findings with existing studies (see Table 5 for summery of results). Schultz (2017) uncovers social 
media content engagement contrariety between food and apparel industry. This suggests that market characteristics affect users' degree of engagement. Preliminary investigations analysed travel agency (Sabate et al., 2014) and diverse industry (de Vries, Gensler and Leeflang, 2012). These data are possible to influence the results of analyses. Another factor that needs consideration is social media platforms under study. Facebook and Instagram's demographic users are varied from each other. The former is popular among older consumers, whereas the latter is dominated by younger users (Jackson, 2019). This difference in age might affect social media consumption and behaviour.

This study advances existing works of literature (Pletikosa Cvijikj and Michahelles, 2011, 2013; de Vries, Gensler and Leeflang, 2012; Sabate et al., 2014; Schultz, 2017) analysing the effect of posting timing on content engagements, which only focus on Facebook. There is a need to discuss such an effect on other social media platforms (de Vries, Gensler and Leeflang, 2012; Schreiner, Fischer and Riedl, 2019). This study attempts to respond to the call by examining the effects of posting days and times on likes and comments on Instagram. By doing such, this study provides a formal and theorygrounded discussion on Instagram content engagements. Such an effort, in the end, expands the social media marketing literature.

\subsection{Managerial Implications}

Food brands (e.g., restaurants, packaged local snacks, street food, and pastry) should post their contents on Instagram during weekdays to receive higher engagements from their followers on Instagram. To inform food brands what day precisely is the best to post, this study unveils the ranks of content engagements from highest to lowest. If brands' goal is to prompt more likes, they should upload their contents more on Friday, followed by Wednesday, Tuesday, Monday, and Thursday. If their objective is to acquire more comments, they should post more on Tuesday, then Wednesday, Monday, Thursday, and Friday. Also, food brands should prioritise their plans to post during breakfast, then followed by lunchtimes to induce more likes and comments. It also should be noted that brands should avoid uploading their Instagram contents during dinner time as it will reduce the number of likes and has no effect on comments.

Such timing occurs because online activities are mostly undertaken during weekdays from schools and workplaces (Golder, Wilkinson and Huberman, 2007; Rutz and Bucklin, 2011). During breakfast and lunch periods on weekdays and in schools or working locations, users might scroll their Instagram accounts to entertain themselves. This increases the probability of brands' posts to be seen by and engaged with
Instagram users. Meanwhile, during weekends and dinner time in the evening, users have no restrictions. They can do anything. Instead of browsing Instagram, they might play games and sports or interact with friends and family.

These findings are beneficial for brands and social media managers. Contents from voluminous sources (e.g., friends, family, and businesses) inundate Instagram feeds. It is plausible posts from brands to be buried and never be seen by their targeted audience (Pletikosa Cvijikj and Michahelles, 2013). This situation accentuates the importance of scheduling incorporation in marketing programme (Kumar, Jacob and Sriskandarajah, 2006). The discoveries of this study provide a solution to such problems. They inform brands and social media managers the most effective posting timing on Instagram. This will guide them to enhance their social media marketing strategy on such a prominent platform.

\section{CONCLUSION, LIMITATIONS, AND FURTHER RESEARCH}

This study initiated the analysis of posting timing on Instagram. The results provide empirical discussion, extend social media marketing literature, and benefit social media managers and brands. Despite the effort and advantages, this study carries some limitations. First, it analysed food brands in Indonesia. Market characteristics affect content engagements (Schultz, 2017). The findings might be irrelevant to other industry and countries. Additionally, this study investigated Instagram. This platform has distinct demographics compared to other media such as Facebook.

The limitations offer opportunities for future studies. Researchers could inspect other industries, such as fashion, sports, and entertainment. They could also use data from other countries, especially those of emerging markets such as India and Brazil. These differences in data usage for analyses could validate whether posting timing on Instagram is significant for brands' effective marketing strategy. Future studies might also examine TikTok and Snapchat. These social platforms are popular. It would be interesting to substantiate the importance of scheduling in the social media marketing strategy. Lastly, based on the control variables and preliminary findings on Facebook, the predictors of followers, fake followers, remuneration, content types, and interactivity affect content engagements (de Vries, Gensler and Leeflang, 2012; Pletikosa Cvijikj and Michahelles, 2013; Sabate et al., 2014; Luarn, Lin and Chiu, 2015; Schultz, 2017). Ensuing investigations might include these variables to verify their influences on Instagram popularity posts. 
7. FIGURES, TABLES, AND REFERENCES 7.1 Figures and Tables

Table 1: Descriptive Statistics of the 40 Brands

\begin{tabular}{|c|c|c|}
\hline & Mean & Std. Deviation \\
\hline Total Followers & 82760.50 & 109637.72 \\
\hline Average Likes & 587.35 & 742.26 \\
\hline Average Comments & 24.18 & 33.84 \\
\hline Likes-to-Followers Ratio & $1.25 \%$ & $2.55 \%$ \\
\hline $\begin{array}{c}\text { Comments-to-Followers } \\
\text { Ratio }\end{array}$ & $0.04 \%$ & $0.05 \%$ \\
\hline & Frequency & $\%$ \\
\hline Fake Followers & 35 & $87.5 \%$ \\
\hline Real Followers & 5 & $12.5 \%$ \\
\hline
\end{tabular}

Table 2: Descriptive Statistics of the Explanatory Variables

\begin{tabular}{|c|c|c|c|}
\hline Variable & Level & Frequency & $\mathbf{\%}$ \\
\hline Day & Sunday & 577 & $19.5 \%$ \\
\hline & Monday & 443 & $15.0 \%$ \\
\hline & Tuesday & 372 & $12.6 \%$ \\
\hline & Wednesday & 357 & $12.1 \%$ \\
\hline & Thursday & 399 & $13.5 \%$ \\
\hline & Friday & 361 & $12.2 \%$ \\
\hline Period & Saturday & 449 & $15.2 \%$ \\
\hline & In-between & 745 & $25.2 \%$ \\
\hline & Breakfast & 462 & $15.6 \%$ \\
\hline Lollowers & Lunch & 878 & $29.7 \%$ \\
\hline Likes & Dinner & 873 & $29.5 \%$ \\
\hline & Fake Followers & 2878 & $97.3 \%$ \\
\hline Remuneration & Real Followers & 80 & $2.7 \%$ \\
\hline & Fake Likes & 1 & $.0 \%$ \\
\hline & Real Likes & 2957 & $100.0 \%$ \\
\hline Total Likes & Remuneration & 50 & $1.7 \%$ \\
\hline & No Remuneration & 2908 & $98.3 \%$ \\
\hline & & & \\
\hline & Mean & Variance & Std. Deviation \\
\hline & 104.36 & 45731.56 & 213.85 \\
\hline
\end{tabular}


Table 3: Estimation Results Based on Days

\begin{tabular}{|c|c|c|c|c|}
\hline & \multicolumn{2}{|c|}{ LnLikes } & \multicolumn{2}{c|}{ LnComments } \\
\cline { 2 - 5 } & $\mathbf{B}$ & Std. Error & $\mathbf{B}$ & Std. Error \\
\hline (Intercept) & $\mathbf{- 4 . 0 0 3}$ & .3482 & $\mathbf{- 1 1 . 0 5 9}$ & .9731 \\
\hline Sunday & - & - & - &. \\
\hline Monday & $\mathbf{. 3 0 3}$ & .0735 & $\mathbf{5 9 5}$ & .1739 \\
\hline Tuesday & $\mathbf{. 3 2 2}$ & .0774 & $\mathbf{. 7 0 5}$ & .1832 \\
\hline Wednesday & $\mathbf{. 3 9 3}$ & .0784 & $\mathbf{. 6 3 7}$ & .1849 \\
\hline Thursday & $\mathbf{. 2 6 2}$ & .0760 & $\mathbf{. 5 2 8}$ & .1796 \\
\hline Friday & $\mathbf{. 4 1 4}$ & .0780 & .389 & .1851 \\
\hline Saturday & .173 & .0733 & .102 & .1745 \\
\hline Number of Followers & $\mathbf{. 8 8 9}$ & .0305 & $\mathbf{1 . 1 6 7}$ & .0863 \\
\hline Real Followers & - & - & - & - \\
\hline Fake Followers & $\mathbf{- 1 . 5 3 4}$ & .1330 & -.976 & .3071 \\
\hline Real Likes & - & - & - & - \\
\hline Fake Likes & .215 & 1.1741 & -2.682 & 2.8716 \\
\hline No Remuneration & - & - & - & - \\
\hline Remuneration & $\mathbf{1 . 9 6 5}$ & .1674 & $\mathbf{1 . 6 5 1}$ & .3867 \\
\hline (Scale) & $1^{\mathrm{a}}$ & & $1^{\mathrm{a}}$ & \\
\hline (Negative binomial) & 1.335 & .0304 & 6.987 & .2862 \\
\hline LR $\chi^{2}(10$, N=2958) & 1469.009 & & 302.595 & .676 \\
\hline Deviance/df & 1.182 & & & \\
\hline
\end{tabular}

Bold figures: $p$-value $<0.01$, Italic figures: $p$-value $<0.05$

Table 4: Estimation Results Based on Times

\begin{tabular}{|c|c|c|c|c|}
\hline & \multicolumn{2}{|c|}{ LnLikes } & \multicolumn{2}{c|}{ LnComments } \\
\hline & $\mathbf{B}$ & Std. Error & $\mathbf{B}$ & Std. Error \\
\hline (Intercept) & $\mathbf{- 3 . 6 2 8}$ & .3469 & $\mathbf{- 1 0 . 0 6 2}$ & .9342 \\
\hline Breakfast & $\mathbf{. 2 9 8}$ & .0687 & $\mathbf{. 7 5 6}$ & .1607 \\
\hline Lunch & $\mathbf{. 3 4}$ & .0583 & $\mathbf{3 7 6}$ & .1374 \\
\hline Dinner & $\mathbf{- . 1 6 0}$ & .0579 & -.184 & .1379 \\
\hline Number of Followers & $\mathbf{. 8 7 6}$ & .0308 & $\mathbf{1 . 1 1 8}$ & .0839 \\
\hline Real Followers & - & - & - & - \\
\hline Fake Followers & $\mathbf{- 1 . 6 0 2}$ & .1324 & $\mathbf{- 1 . 2 7 5}$ & .3064 \\
\hline Real Likes & - & - & - & - \\
\hline Likes & .014 & 1.1691 & -3.149 & 2.8495 \\
\hline No Remuneration & - & - & - & .3821 \\
\hline Remuneration & $\mathbf{1 . 9 4 9}$ & .1667 & $\mathbf{1 . 7 5 5}$ & .2830 \\
\hline (Scale) & 1 a & & 1 a & \\
\hline Legative binomial) & 1.325 & .0302 & 6.877 & \\
\hline Deviance/df & 1497.904 & & 320.785 & \\
\hline
\end{tabular}

Bold figures: $\mathrm{p}$-value $<0.01$ 
Table 5: Summary of Results

\begin{tabular}{|c|c|c|}
\hline Hypotheses & Expected & Number of Likes \\
\hline $\begin{array}{c}\text { H1a: Weekdays (Monday, Tuesday, Wednesday, } \\
\text { Thursday, Friday) }\end{array}$ & - & Not Supported \\
\hline H2a: Breakfast & + & Supported \\
\hline H2b: Lunch & + & Supported \\
\hline H2c: Dinner & - & Supported \\
\hline Hypotheses & Expected & Supported \\
\hline $\begin{array}{c}\text { H1b: Weekdays (Monday, Tuesday, Wednesday, } \\
\text { Thursday, Friday) }\end{array}$ & + & Supported \\
\hline H2d: Breakfast & + & Supported \\
\hline H2e: Lunch & + & Not Supported \\
\hline H2f: Dinner & - & \\
\hline
\end{tabular}

\subsection{REFERENCES}

1. Ainin, S. et al. (2015) 'Factors influencing the use of social media by SMEs and its performance outcomes', Industrial Management and Data Systems, 115(3), pp. 570-588. doi: 10.1108/IMDS-07-2014-0205.

2. Angulo, N. (2016) Brand marketers see higher engagement with micro-influencers: Survey, Marketing Dive. Available at: https://www.marketingdive.com/news/brandmarketers-see-higher-engagement-with-microinfluencers-survey/418109/ (Accessed: 27 December 2019).

3. Bender, J. L., Jimenez-Marroquin, M. C. and Jadad, A. R. (2011) 'Seeking support on facebook: A content analysis of breast cancer groups', Journal of Medical Internet Research, 13(1). doi: 10.2196/jmir.1560.

4. Beukeboom, C. J., Kerkhof, P. and de Vries, M. (2015) 'Does a Virtual Like Cause Actual Liking? How Following a Brand's Facebook Updates Enhances Brand Evaluations and Purchase Intention', Journal of Interactive Marketing. Marketing EDGE.org., 32, pp. 26-36. doi: 10.1016/j.intmar.2015.09.003.

5. Cameron, A. C. and Trivedi, P. K. (2013) Regression Analysis of Count Data. 2nd Editio. Cambridge University Press.

6. Casaló, L., Flavián, C. and Guinalíu, M. (2007) 'The impact of participation in virtual brand communities on consumer trust and loyalty: The case of free software', Online Information Review, 31(6), pp. 775-792. doi: $10.1108 / 14684520710841766$.

7. Chi, C. (2020) When Is the Best Time to Post on Instagram in 2020? [Cheat Sheet], HubSpot. Available https://blog.hubspot.com/marketing/instagrambest-time-post (Accessed: 3 January 2020).

8. Golder, S. A., Wilkinson, D. and Huberman, B. A. (2007) Rhythms of Social Interaction: Messaging Within. Communitie. Edited by C. Steinfield et al. London: Springer. doi: https://doi.org/10.1007/978-1-84628-905-7_3.

9. Hudson, S. et al. (2016) The influence of social media interactions on consumer-brand relationships: A three-country study of brand perceptions and marketing behaviors, International Journal of Research in Marketing. Elsevier B.V. doi: 10.1016/j.ijresmar.2015.06.004.

10. Jackson, D. (2019) Instagram vs Facebook: which is best for your brand's strategy?, Sprout Social. Available at: https://sproutsocial.com/insights/instagram-vsfacebook/ (Accessed: 27 December 2019).

11. Jones, C. (2020) The Best Time to Post on Instagram [Updated], ExpertVoice. Available at: https://www.expertvoice.com/the-best-times-topost-on-instagram/ (Accessed: 27 December 2019).

12. Kabadayi, S. and Price, K. (2014) 'ConsumerBrand engagement on Facebook: liking and commenting behaviors', Journal of Research in Interactive Marketing, 8(3), pp. 203-223. doi: 10.1108/JRIM-12-2013-0081.

13. Kumar, S., Jacob, V. S. and Sriskandarajah, C. (2006) 'Scheduling advertisements on a web page to maximize revenue', European Journal of Operational Research, 173(3), pp. 1067-1089. doi: 10.1016/j.ejor.2005.07.005.

14. Lagrosen, S. O. and Grundén, K. (2014) 'Social media marketing in the wellness industry', TQM Journal, 26(3), pp. 253-260. doi: 10.1108/TQM12-2013-0129.

15. Lehmann, J. et al. (2012) Models of user engagement. User model. Edited by J. Masthoff et al. Berlin: Springer.

16. Loren, T. (2020) The Best Time to Post on Instagram in 2020, According to 12 Million Posts, Later. Available at: https://later.com/blog/best-time-to-post-oninstagram/ (Accessed: 27 December 2019).

17. Luarn, P., Lin, Y. F. and Chiu, Y. P. (2015) 'Influence of Facebook brand-page posts on online engagement', Online Information Review, 39(4), pp. 505-519. doi: 10.1108/OIR-01-20150029.

18. McCorkindale, T. (2010) 'Can you see the writing on my wall? A content analysis of the 
Fortune 50's Facebook social networking sites', Public Relations Journal, 4(3), pp. 1-13. doi: 10.1558/jsrnc.v4il.24.

19. Mohsin, M. (Oberlo) (2020) 10 Instagram Stats Every Marketer Should Know in 2020 [Infographic], Oberlo. Available at: https://www.oberlo.com/blog/instagram-statsevery-marketer-should-know (Accessed: 1 March 2020).

20. Newberry, C. (2019) Illustration of two people climbing a line graph37 Instagram Stats That Matter to Marketers in 2020, Hootsuite. Available at: https://blog.hootsuite.com/instagram-statistics/ (Accessed: 27 October 2019).

21. Osman, M. (2020) Here's Why You Should Never Buy Instagram Likes, Sprout Social. Available at: https://sproutsocial.com/insights/buy-instagramlikes/(Accessed: 10 May 2020).

22. Pinto, M. B. and Yagnik, A. (2017) 'Fit for life: A content analysis of fitness tracker brands use of Facebook in social media marketing', Journal of Brand Management. Palgrave Macmillan UK, 24(1), pp. 49-67. doi: 10.1057/s41262-016-00144.

23. Pletikosa Cvijikj, I. and Michahelles, F. (2011) 'A case study of the effects of moderator posts within a facebook brand page', Lecture Notes in Computer Science (including subseries Lecture Notes in Artificial Intelligence and Lecture Notes in Bioinformatics), 6984 LNCS, pp. 161-170. doi: 10.1007/978-3-642-24704-0_21.

24. Pletikosa Cvijikj, I. and Michahelles, F. (2013) 'Online engagement factors on Facebook brand pages', Social Network Analysis and Mining, 3(4), pp. 843-861. doi: 10.1007/s13278-0130098-8.

25. Rishika, R. et al. (2013) 'The Effect of Customers' Social Media Participation on Customer Visit Frequency and Profitability: An Empirical Investigation', Information Systems Research, 24(1), pp. 108-127. doi: https://doi.org/10.1287/isre.1120.0460.

26. Rutz, O. J. and Bucklin, R. E. (2011) 'From Generic to Branded: A Model of Spillover Dynamics in Paid Search Advertising', Journal of Marketing Research, 48(1), pp. 87-102. doi: https://doi.org/10.1509\%2Fjmkr.48.1.87.

27. Sabate, F. et al. (2014) 'Factors influencing popularity of branded content in Facebook fan pages', European Management Journal. Elsevier Ltd, 32(6), pp. 1001-1011. doi: 10.1016/j.emj.2014.05.001.

28. Schau, H. J., Jr, A. M. M. and Arnould, E. J. (2009) 'Schau How Brand Community Practices Create Value.pdf', 73(September), pp. 30-51.

29. Schreiner, M., Fischer, T. and Riedl, R. (2019) 'Impact of content characteristics and emotion on behavioral engagement in social media: literature review and research agenda', Electronic Commerce Research. Springer US, (0123456789). doi: 10.1007/s10660-019-093538.
30. Schultz, C. D. (2017) 'Proposing to your fans: Which brand post characteristics drive consumer engagement activities on social media brand pages?', Electronic Commerce Research and Applications. Elsevier B.V., 26, pp. 23-34. doi: 10.1016/j.elerap.2017.09.005.

31. Shen, B. and Bissell, K. (2013) 'Social Media, Social Me: A Content Analysis of Beauty Companies' Use of Facebook in Marketing and Branding', Journal of Promotion Management, 19(5), pp. 629-651. doi: 10.1080/10496491.2013.829160.

32. Tomov, T. (2019) Influencer Checkup - How To Successfully Avoid Fake Influencers, Semrush. Available

https://www.semrush.com/blog/how-to-

successfully-avoid-fake-influencers/ (Accessed: 27 December 2019).

33. Vries, E. L. E. De (2019) 'When more likes is not better: the consequences of high and low likesto-followers ratios for perceived account credibility and social media marketing effectiveness', Marketing Letters. Marketing Letters, $p .17$.

34. de Vries, L., Gensler, S. and Leeflang, P. S. H. (2012) 'Popularity of Brand Posts on Brand Fan Pages: An Investigation of the Effects of Social Media Marketing', Journal of Interactive Marketing, 26(2), pp. 83-91. doi: 10.1016/j.intmar.2012.01.003.

35. De Vries, N. J. and Carlson, J. (2014) 'Examining the drivers and brand performance implications of customer engagement with brands in the social media environment', Journal of Brand Management. Nature Publishing Group, 21(6), pp. 495-515. doi: 10.1057/bm.2014.18.

36. Wallace, L., Wilson, J. and Miloch, K. (2011) 'Sporting Facebook: A content analysis of NCAA organizational sport pages and Big 12 conference athletic department pages', International Journal of Sport Communication, 4(4), pp. 422-444. 